\title{
Attitudes towards free-roaming dogs and dog ownership practices in Bulgaria, Italy, and Ukraine
}

\author{
Lauren Margaret Smith $\oplus^{1 *}$, Rupert Quinnell $\odot^{1}$, Alexandru Munteanu ${ }^{2}$, Sabine Hartmann ${ }^{2}$, \\ Paolo Dalla Villa ${ }^{3,4}$, Lisa Collins ${ }^{1 *}$ \\ 1 School of Biology, Faculty of Biological Sciences, University of Leeds, Leeds, United Kingdom, 2 VIER \\ PFOTEN International, Vienna, Austria, 3 Istituto Zooprofilattico Sperimentale dell'Abruzzo e del Molise "G. \\ Caporale", Teramo, Italy, 4 World Organization for Animal Health, OIE Sub-Regional Representation in \\ Brussels, Brussels, Belgium \\ * L.Collins@ @leeds.ac.uk (LC); lauren.m.smith026@ gmail.com (LMS)
}

\section{OPEnACCESS}

Citation: Smith LM, Quinnell R, Munteanu A, Hartmann S, Dalla Villa P, Collins L (2022) Attitudes towards free-roaming dogs and dog ownership practices in Bulgaria, Italy, and Ukraine. PLoS ONE 17(3): e0252368. https://doi.org/ 10.1371/journal.pone.0252368

Editor: I. Anna S. Olsson, Universidade do Porto Instituto de Biologia Molecular e Celular, PORTUGAL

Received: May 12, 2021

Accepted: February 16, 2022

Published: March 2, 2022

Peer Review History: PLOS recognizes the benefits of transparency in the peer review process; therefore, we enable the publication of all of the content of peer review and author responses alongside final, published articles. The editorial history of this article is available here: https://doi.org/10.1371/journal.pone.0252368

Copyright: @ 2022 Smith et al. This is an open access article distributed under the terms of the Creative Commons Attribution License, which permits unrestricted use, distribution, and reproduction in any medium, provided the original author and source are credited.

Data Availability Statement: All data, code and supporting files are available from the Open Science Framework database: https://osf.io/dkxbz/

\section{Abstract}

Free-roaming dog population management is conducted to mitigate risks to public health, livestock losses, wildlife conservation, and dog health and welfare. This study aimed to determine attitudes towards free-roaming dogs and their management and describe dog ownership practices in three European countries. We distributed an online questionnaire comprising questions relating to dog ownership practices and attitudes towards free-roaming dogs using social media. We used logistic regression and ordinal probit models to determine associations between demographic and other factors with ownership practices and attitudes towards free-roaming dogs. This study found that most surveyed respondents wanted to see a reduction in free-roaming dog numbers, and felt that this should be achieved through sheltering, catch-neuter-release, and by controlling owned dog breeding. We identified significant associations between both attitudes and ownership practices with gender, religious beliefs, age, education level, reason for dog ownership, previous experience with freeroaming dogs, and country of residence. Respondents who identified as: (i) male, (ii) holding religious beliefs, (iii) owning dogs for practical reasons, (iv) being young, or (v) having no schooling or primary education had a lower probability of neutering and a higher probability of allowing dogs to roam. Respondents who identified as: (i) female, (ii) feeling threatened by free-roaming dogs, (iii) older, or (iv) having more education had a higher probability of answering that increases in free-roaming dog numbers should be prevented. These findings can help to inform future dog population management interventions in these countries. We emphasise the importance of considering local attitudes and dog ownership practices in the development of effective dog population management approaches.

\section{Introduction}

Domestic dogs (Canis familiaris) are one of the most abundant species of canids in the world, with total population estimates between 700 million to 1 billion $[1,2]$. Around $75 \%$ of this 
?view_only=

5b421d2488144d3a8f6a313ebe30864d.

Funding: LMC has received a research grant from VIER PFOTEN International (https://www.fourpaws.org); and LMS's research has been funded by VIER PFOTEN International. SH and AMM are employed by VIER PFOTEN International and contributed to the conceptualisation of the study and reviewing and editing of drafts.

Competing interests: The authors declare that: $A$. M.M. and S.H. are employed by VIER PFOTEN International, a global animal welfare organisation; L.M.C has received a research grant from VIER PFOTEN International; and L.M.S.'s research has been funded by VIER PFOTEN International. This does not alter our adherence to PLOS ONE policies on sharing data and materials. population are classified as "free-roaming", indicating their ability to roam and reproduce freely [1]. Where free-roaming dogs exist in high densities, there are important implications for public health [3-5], livestock losses [6-10] and wildlife conservation [11-13], in addition to issues for the welfare of the dogs themselves [14-17]. The management methods applied to control population sizes involve culling, reproductive control (e.g. through catch-neuterrelease; CNR), and the use of shelters to house unowned or unwanted dogs [18].

Human behaviour can shape the success of a population management programme. This includes actions of local communities, the teams involved in dog population management and the governments imposing management interventions. Indeed, the World Organisation for Animal Health (OIE) has identified that understanding public attitudes is important for developing effective dog population control [19]. In order for interventions to be successful, there must be public support for both the management method and its aims (e.g. reducing or stabilising the number of free-roaming dogs). Different communities may have different attitudes towards free-roaming dogs and management methods due to culture, religion, and the specific risks to humans, wildlife, livestock, and other companion animals in the area. Organisations involved in dog population management should consider these cultural, religious, and risk factors to ensure interventions are effective. For example, free-roaming dog populations can be an important part of a community, providing protection to people and livestock [17]. Where management methods aim to reduce free-roaming dog numbers, there may still be demand for dogs in a community. Unless this demand reduces, new dogs may be acquired to replace those removed by population management (either bought, adopted, or by uncontrolled immigration of free-roaming dogs). Prior to implementing management interventions, the level of acceptance of free-roaming dogs in the area should be gauged (i.e. determine whether the public prefer to have fewer free-roaming dogs in the community) so that those involved in dog population management can work towards a goal that benefits the community.

Dog ownership practices can also influence the success of population management. Encouraging responsible ownership practices is included as an objective in Chapter 7.7 of the OIE Terrestrial Animal Health Code on free-roaming dog population control [19]. The OIE describes the requirements of responsible ownership as: "When a person takes on the ownership of a dog, there should be an immediate acceptance of responsibility for the dog, and for any offspring it may produce, for the duration of its life or until a subsequent owner is found" [19]. Unrestricted owned dogs (free-roaming owned) and abandoned dogs are sources of freeroaming dog population increase [19]. Dog ownership practices that allow owned dogs to roam and do not prevent reproduction can hinder efforts to control free-roaming dog populations. Those involved in dog population management must determine the extent to which owned dogs contribute to the free-roaming dog population so that management interventions can be tailored appropriately (e.g. by enforcing responsible ownership through legislation and education programmes).

Questionnaire surveys are frequently used to gain insight into attitudes, opinions, behaviours, and the demographic and sociological factors associated with these. In terms of dog population management, different attitudes, opinions and behaviours about and towards dogs have been associated with responder gender [20-24], age [20, 22, 25], education [21, 22, 26], and previous life experiences (e.g. experience of keeping dogs in childhood) [27]. Questionnaires aiming to describe dog ownership, attitudes, and knowledge have been conducted in many countries around the world, but few published studies have been carried out in European countries.

This study determines attitudes towards the presence of free-roaming dogs and of dog ownership practices in three European countries-Bulgaria, Italy, and Ukraine. We selected these focal countries due to the networks established with collaborating organisations (VIER 
PFOTEN International and Istituto Zooprofilattico Sperimentale dell'Abruzzo e del Molise "Giuseppe Caporale"; IZSAM) that provided local knowledge to facilitate data collection. The focal countries are culturally and environmentally distinct, allowing comparison of the collected data between different countries within Europe.

In this study, we define attitudes as the thoughts, feelings, and opinions of respondents, as reported in the questionnaire. We define ownership practices as the actions taken to acquire, provide care, and relinquish ownership of dogs, as reported in the questionnaire. The objectives of this study are to: (i) determine attitudes towards the presence of free-roaming dogs; (ii) determine local ownership practices and attitudes, including whether owned dogs were freeroaming or neutered, the level of dog abandonment, and the reasons for dog abandonment; and (iii) investigate whether demographic and other factors (including age, gender, education level, religious beliefs, and previous experience with dogs) influence ownership practices and attitudes towards free-roaming dogs. This information can inform interventions so that education campaigns can target groups who are at-risk of irresponsible dog ownership behaviours $[20,26]$, as well as provide a baseline for evaluating the impact of interventions on human behaviour and attitudes [26].

\section{Materials and methods}

\section{Study design}

This was a cross-sectional study, with target populations of Bulgaria, Italy, and Ukraine. The study populations were residents who used social media. Participants were recruited through social media using an online questionnaire (Online Surveys [28]) that was open between the $8^{\text {th }}$ of March 2019 and the $21^{\text {st }}$ of December 2019, available in four languages: Bulgarian, Italian, Ukrainian, and Russian. The social media outlets used to distribute the questionnaire included Facebook [29] and Twitter [30]. Facebook advertising was used to increase the visibility of the questionnaire to the study population and increase the number of respondents. Facebook advertising targeted Facebook users who: (i) were recorded in their online profile as living in Bulgaria, Italy, or Ukraine; and (ii) were over the age of 18 . The Facebook adverts invited respondents to provide their opinion on free-roaming dogs and dog ownership practices (see S1 File for English translation of adverts). All adverts were used in all countries to an equal extent, though it is not possible to know which advert respondents had seen. Minimum sample sizes were calculated for the three study areas, using Eq 1. A sample size of 385 respondents per study country was necessary to provide estimates with a $95 \%$ confidence interval that was within a $5 \%$ margin of error.

Eq 1. Sample size calculation

$$
\text { Sample size }=\frac{\frac{z^{2} \times p(1-p)}{e^{2}}}{1+\left(\frac{z^{2} \times p(1-p)}{e^{2} N}\right)}
$$

Where $\mathrm{N}=$ population size, $\mathrm{e}=$ margin of error, $\mathrm{z}=\mathrm{z}$-score, $\mathrm{p}=$ population proportion.

\section{Ethical approval}

Prior to completing the questionnaire, all participants gave consent within the online survey through a digital signature by selecting yes in a tick box to confirm that they (i) had read and understood the information sheet explaining the project (S2 File), (ii) understood that they had the opportunity to ask questions about the project, (iii) knew they could withdraw from completing the questionnaire, prior to submitting, (iv) agreed for their responses to be collected, stored, and analysed in an anonymised form for the purpose of reports and publication 
(see S2 File for information). Those who did not consent were not able to complete the questionnaire and were therefore not included in the study. No directly identifiable information was collected; all data obtained remains anonymous. Participants were able to withdraw from the questionnaire prior to completion, but as the data was collected anonymously, participants could not withdraw after the questionnaire was submitted. No minors were included in this study, as respondents who reported being under the age of 18 were not able to complete the online questionnaire. The study was approved by the University of Leeds Ethical Committee (reference BIOSCI 17-003).

\section{Questionnaire design}

The questionnaire was developed in English and translated into Bulgarian, Italian, Ukrainian, and Russian. The questionnaire comprised closed questions regarding the respondents' attitudes towards free-roaming dogs and their management. Respondents that reported owning a dog were asked to also complete questions relating to dog ownership practices. Likert-type scales were used to estimate the level of agreement with specific questions. The questionnaire consisted of three sections: (i) socio-demographic information of the respondent (all respondents); (ii) ownership practices (only dog owners); and (iii) attitudes towards the presence of free-roaming dogs and the management of the free-roaming dog population (all respondents). A copy of the questionnaire in English can be found in S2 File.

\section{Statistical analyses}

All predictor and response variables are described in Table 1. Bernoulli logistic regression models were used to test associations between demographic parameters and respondent

Table 1. Response and predictor variables (self-reported responses to questions) included in the statistical analyses and their levels.

\begin{tabular}{|c|c|}
\hline Variables & Levels \\
\hline Age & ${ }^{*} 18-24,25-34,35-44,45-54,55-64,65-74$ and 75 and above \\
\hline Children in household & Children in household, no children in household \\
\hline Country & Bulgaria, Italy, Ukraine \\
\hline Dog ownership & Dog owner, non-dog owner \\
\hline Education status & ${ }^{*}$ No education, primary, secondary, tertiary \\
\hline Gender & Male, Female, NA (including option Other) \\
\hline Neutering status of owned dogs & Neutered, not neutered \\
\hline Owning a dog for practical reasons & Practical, not practical \\
\hline Religious belief & Religious, non-religious \\
\hline Feeling physically threatened by dogs on the street & $\begin{array}{l}\text { * Strongly disagree, disagree, neither agree nor disagree, agree, } \\
\text { strongly agree }\end{array}$ \\
\hline Been attacked by dogs on the street & Been attacked, not been attacked \\
\hline $\begin{array}{l}\text { Respondent or family members have been bitten by } \\
\text { dogs on the street in last } 12 \text { months }\end{array}$ & Been bitten, not been bitten \\
\hline Roaming status of owned dogs & Never, Sometimes, Always \\
\hline $\begin{array}{l}\text { I do not like the presence of free-roaming dogs } \\
\text { around my home or work }\end{array}$ & $\begin{array}{l}\text { Strongly disagree, disagree, neither agree nor disagree, agree, } \\
\text { strongly agree }\end{array}$ \\
\hline Should an increase in dogs on the street be prevented? & Yes, No \\
\hline Would you prefer to see dogs on the street? & $\begin{array}{l}\text { No free-roaming dogs, fewer free-roaming dogs, do not mind } \\
\text { free-roaming dogs, more free-roaming dogs }\end{array}$ \\
\hline
\end{tabular}

* Ordinal predictor variables analysed as continuous variables in statistical models.

https://doi.org/10.1371/journal.pone.0252368.t001 
experience on the binary response variables: (i) Neutering status of owned dogs (binary response: neutered/not neutered); and (ii) respondents' answers to the question "Do you think an increase in dogs on the street should be prevented?" (binary response: Yes/no). Ordinal probit models [31] were used to test associations between demographic parameters and respondent experience on: (i) Roaming status of owned dogs; (ii) I do not like the presence of free-roaming dogs around my home or work; and (iii) respondents' answers to the question "Would you prefer to see: no free-roaming dogs, fewer free-roaming dogs, do not mind free-roaming dogs, more free-roaming dogs". Ordinal variables are categorical variables with a natural order, for example Likert-type scales [32]. Ordinal variables are assumed to have an underlying continuous latent variable that cannot be measured directly (e.g. the attitude of a respondent). This underlying latent variable is therefore split into discrete options that can be measured (e.g. Strongly agree or Agree). The intervals between these discrete options may not be equal (i.e. not equidistant), an assumption required by metric models [33], and responses to ordinal questions may have non-normal distributions. Ordinal predictor variables can be problematic if analysed metrically, leading to Type I (false positive) and Type II (false negative) errors [31]. Ordinal models deal with issues in potential non-equidistant responses and non-normal distributions.

Dog ownership practices. Model 1 tested associations between demographic parameters and respondent experience with neutering of owned dogs using a Bayesian Bernoulli logistic regression model. The response variable was neutering status of owned dogs with fixed effects of gender, age, education status, religious belief, owning a dog for practical reasons and country (Table 1). Model 2 tested associations between demographic parameters and respondent experience with the roaming status of owned dogs using a Bayesian ordinal probit model. The response variable was roaming status of owned dogs and fixed effects were the same as for Model 1.

Attitudes towards free-roaming dogs. Model 3 tested associations between demographic parameters and respondent experience with agreement to the statement $I$ do not like the presence of free-roaming dogs around my home or work using a Bayesian ordinal probit model. The response variable was I do not like the presence of free-roaming dogs around my home or work and fixed effects were dog ownership, gender, age, education status, children in household, feeling physically threatened by dogs on the street, been attacked by dogs on street, respondent or family members have been bitten by dogs on the street in last 12 months, and country.

Model 4 tested associations between demographic parameters and respondent experience with the question Do you think an increase in dogs on the street should be prevented? using a Bayesian Bernoulli logistic regression model. The response variable was should an increase in dogs on the street be prevented, with fixed effects the same as in Model 3.

Model 5 tested associations between demographic parameters and respondent experience with response to the question Would you prefer to see: no free-roaming dogs, fewer free-roaming dogs, do not mind free-roaming dogs, more free-roaming dogs using a Bayesian ordinal probit model. The response variable was Would you prefer to see dogs on the street, with fixed effects the same as in Model 3.

To fit the statistical models using a Bayesian analysis framework, the package "brms" version 2.12.0 [34] was used in R version 3.6.1 [35]. All models were run with four chains, each with 2000 iterations (1000 used for warmup and 1000 for sampling). Thinning was set to one. The total number of post-warmup samples was 4000 . Where a response was missing (i.e. a respondent did not answer a question), the response was omitted from the statistical analysis (see S1 Table for number of no responses per variable).

Collinearity in the predictor variables was checked using the "vif" function in R package "car" [36] and values lower than three were considered not collinear. Model parameters were summarised by the mean and $95 \%$ credible intervals of the posterior distribution (CI; $95 \%$ 
most probable values). A significant association was determined if the $95 \%$ credible intervals of the posterior distribution did not contain zero on the log odds or probit scale. Probabilities were converted from the logit scale to the probability scale by ${ }^{\mathrm{e}} \mathrm{xp}(x) /{ }_{1}+(\exp (x))$, and are converted to odds using $\exp (x)$, where $x$ is the posterior value on the logit scale.

\section{Results}

\section{Descriptive analyses}

Demographics. The numbers of respondents were 5,434 in Bulgaria, 3,468 in Italy, and 19,323 in Ukraine. All demographic information is provided in S2 Table. Respondents were from multiple regions within Bulgaria, Italy, and Ukraine (see S3 to S5 Tables). A broad range of ages between 18 and 64 were represented in all three study countries. Most respondents were female in all three study countries $(87.5 \%, \mathrm{n}=4,754$ of 5,434, in Bulgaria, $83.1 \%$, $\mathrm{n}=2,882$ of 3,468 in Italy, and $87.1 \%, \mathrm{n}=16,832$ of 19,323 in Ukraine). In Bulgaria $68.9 \%$ $(n=3,743$ of 5,434$)$, in Italy $42.0 \%(n=1,457$ of 3,468$)$, and in Ukraine $67.3 \%(n=13,011$ of $19,323)$ of the respondents considered themselves to be religious. In Bulgaria $36 \%(n=1,970$ of 5,434), Italy $43 \%(n=1,474$ of 3,468) and Ukraine $57 \%(n=10,928$ of 19,323$)$ of respondents lived in households with children.

Ownership practices. Sixty-five percent of respondents in Bulgaria $(n=3,528$ of 5,434), $75 \%$ in Italy $(n=2,581$ of 3,468$)$ and $56 \%$ in Ukraine $(n=10,797$ of 19,323$)$ reported owning a dog. The main reason for dog ownership in all three study countries was for pleasure and company (Bulgaria $85.5 \%, \mathrm{n}=3,017$ of 3528 , Italy $87.7 \%, \mathrm{n}=2,263$ of 2,581, Ukraine $70.7 \%$, $\mathrm{n}=7,631$ of 10,797; see S6 Table for detailed responses on ownership practices). In Italy, a higher percentage of respondents acquired their dog from a dog shelter $(38.1 \%, \mathrm{n}=986$ of $2,581)$, compared to in Bulgaria $(9.7 \%, \mathrm{n}=341$ of 3,528) and Ukraine $(9.9 \%, \mathrm{n}=1,070$ of 10,797) (Fig 1). In Bulgaria and Ukraine, more respondents found their dog on the street (Bulgaria $35.5 \%, \mathrm{n}=1,252$ of 3,528 , and Ukraine $34.6 \%, \mathrm{n}=3,734$ of 10,797 ) or received their dog from friends/family (Bulgaria 32.6\%, $\mathrm{n}=1,149$ of 3,528 and Ukraine $27.9 \%, \mathrm{n}=3,015$ of $10,797)$. More respondents in Italy answered that they prevent their dog from breeding through neutering $(65.4 \%, \mathrm{n}=1,689$ of 2,581$)$, compared to $40.4 \%(\mathrm{n}=1,424$ of 3,528$)$ in Bulgaria and $35.4 \%(\mathrm{n}=3,828$ of 10,797$)$ in Ukraine. When asked the reason why respondents did not prevent breeding, 37.6\% ( $\mathrm{n}=82$ of 218) of respondents in Bulgaria, $34.6 \%(\mathrm{n}=75$ of 217) in Italy, and $13.7 \%(\mathrm{n}=242$ of 1770$)$ in Ukraine answered: "A dog should reproduce at least once" (Fig 1). When respondents were asked if they allowed their dog to roam outside unsupervised, $59.0 \%(\mathrm{n}=2,082$ of 3,528) in Bulgaria, $92.1 \%(\mathrm{n}=2,377$ of 2,581) in Italy and $79.4 \%$ $(\mathrm{n}=8,571$ of 10,797) in Ukraine responded Never, and 29.5\% $(\mathrm{n}=1,039$ of 3,528) in Bulgaria, $6.3 \%(\mathrm{n}=162$ of 2,581$)$ in Italy and $16.3 \%(\mathrm{n}=1764$ of 10,797$)$ in Ukraine responded Sometimes.

Most respondents in all study countries responded that they had never given up a dog (Bulgaria $98.5 \%, \mathrm{n}=3,474$ of 3,528, Italy $92.4 \%, \mathrm{n}=2,386$ of 2,581 , and Ukraine $92.2 \%, \mathrm{n}=9950$ of 10,797). Those respondents who had given up a dog mostly answered that this was because of an Animal behavioural problem (Bulgaria 27.3\%, $\mathrm{n}=9$ of 33, Italy $36.5 \%, \mathrm{n}=66$ of 179 , and Ukraine $23.8 \%, \mathrm{n}=161$ of 676 ), or Other reason (Bulgaria $39.4 \%, \mathrm{n}=13$ of 33 , Italy $57.5 \%$, $\mathrm{n}=104$ of 179 , and Ukraine $45.3 \%, \mathrm{n}=306$ of 676) (Fig 1), such as family illness; a change in circumstances (e.g. birth of new child in home); moving home; owners going on a long trip away; the dog having puppies; or the dog not getting along with other dogs in the household.

Attitudes. In Bulgaria and Ukraine, high percentages of respondents had seen a freeroaming dog on the day they filled in the questionnaire $(73.3 \%, \mathrm{n}=3,983$ of 5,434 , and $77.3 \%$, $\mathrm{n}=14,934$ of 19,323 respectively $)$, compared to only $15.4 \%(\mathrm{n}=534$ of 3,468$)$ of respondents 


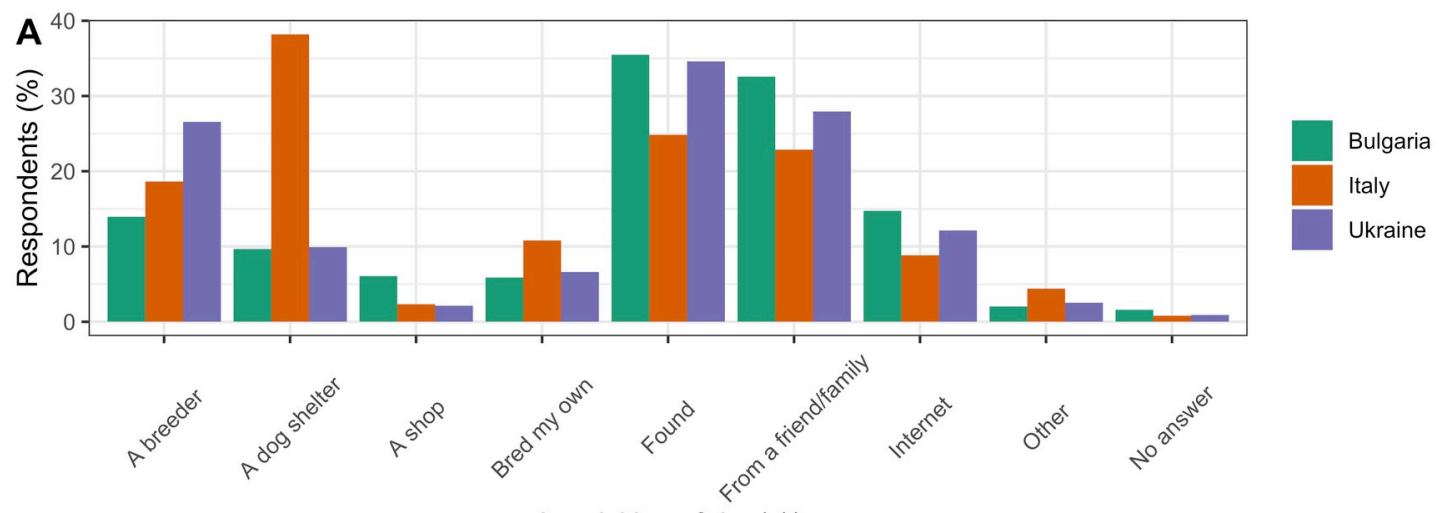

Acquisition of dog(s) ${ }^{*}$

B

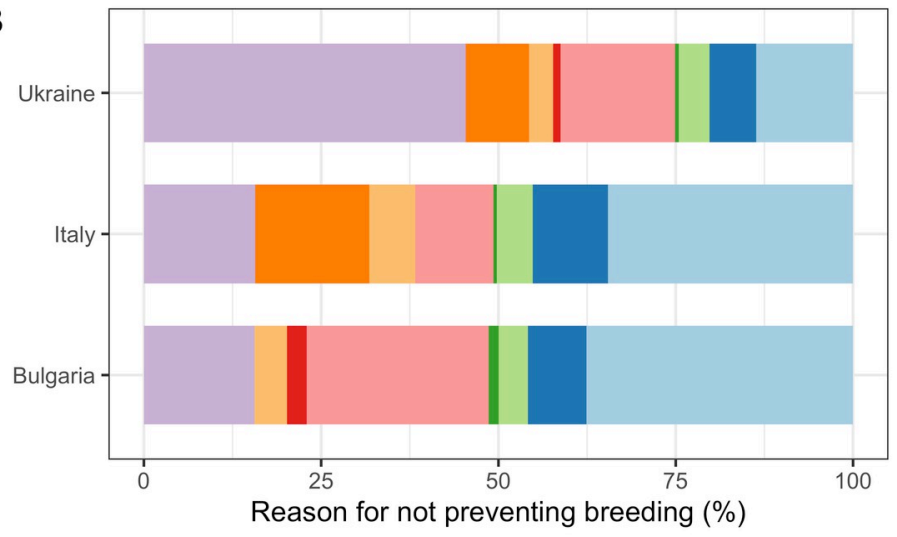

A dog should reproduce at least once

Believe dog is too young to be neutered Cost

Neutering causes weight gain

Neutering is a risk to the dog health

Neutering is against religious beliefs

Neutering modifies the dog behaviour

Other

No answer

C

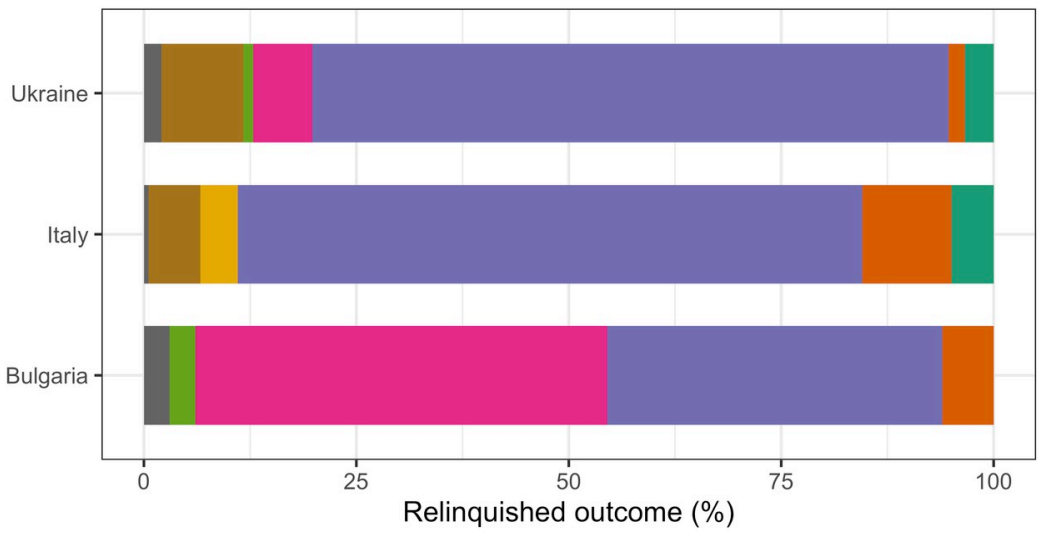

Sell

Give the dog to a shelter

Give to friend

Let free

Euthanise at a clinic

Phone authorities

Other

No answer

D



Animal behavioural problem Cost

Lost interest

Ran away

Other

No answer

Relinquished reason (\%) 
Fig 1. Ownership practices of respondents in Bulgaria, Italy, and Ukraine. The percentage of respondents who answered each of the answer options regarding (A) acquisition of dog, (B) reasons for not preventing breeding, (C) the outcome of the dog, and (D) reason for relinquishment. * Multi answer question: Percentage of respondents who selected each answer option (i.e. 100\% would indicate that all respondents chose this option).

https://doi.org/10.1371/journal.pone.0252368.g001

in Italy (Fig 2; see $\mathrm{S} 7$ Table for detailed results). A higher percentage of respondents in Bulgaria $(21.6 \%, \mathrm{n}=1,174$ of 5,434$)$ and Ukraine $(26.5 \%, \mathrm{n}=5,129$ of 19,323$)$ had been attacked by dogs on the street ever in their lifetime, compared to few $(4.2 \%, \mathrm{n}=147$ of 3,468$)$ in Italy. Higher percentages of respondents in Bulgaria answered that they provided care to free-roaming dogs by giving food $(90.6 \%, \mathrm{n}=4,911$ of 5,434$)$, water $(71.0 \%, \mathrm{n}=3,847$ of 5,434), and shelter $(34.8 \%, \mathrm{n}=1,886$ of 5,434$)$, compared to Italy $(53.7 \%, \mathrm{n}=1831$ food, $44.2 \%, \mathrm{n}=1508$ water, $19.0 \%, \mathrm{n}=647$ of 3468 shelter) and Ukraine $(67.5 \%, \mathrm{n}=13,045$ food, $29.6 \%, \mathrm{n}=5,721$ water and $9.7 \%, \mathrm{n}=1,882$ of 19,323 shelter) (S6 Table).

When respondents were asked their level of agreement with the statement "I do not like free-roaming dogs being present in the streets around my home or work", responses were varied across the full range of options between strongly disagree and strongly agree in Bulgaria and Ukraine (varying between 14 and 25\% for all answer options) (Fig 2). Most respondents in Italy strongly disagreed with this statement $(35.8 \%, \mathrm{n}=1,242$ of 3,468$)$. In all three study countries, most respondents disagreed (Bulgaria $20.8 \%, \mathrm{n}=1,130$ of 5,434 , Italy $19.3 \%, \mathrm{n}=671$ of 3,468 , and Ukraine $25.3 \%, \mathrm{n}=4,890$ of 19,323) and strongly disagreed (Bulgaria $42.2 \%$, $\mathrm{n}=2,295$ of 5,434 , Italy $56.4 \%, \mathrm{n}=1,956$ of 3,468 and Ukraine $31.6 \%, \mathrm{n}=6,097$ of 19,323 ) with the statement "I feel physically threatened by free-roaming dogs".

Respondents answered most often that the municipality government and volunteer organisations should be responsible for managing the free-roaming dog population (Fig 3; S6 Table). Respondents most often answered that they would like to see no (Bulgaria $52.4 \%, \mathrm{n}=2,848$ of 5,434 , Italy $70.2 \%, \mathrm{n}=2,435$ of 3,468, and Ukraine $45.2 \%, \mathrm{n}=8,740$ of 19,323) and fewer (Bulgaria $32.8 \%, \mathrm{n}=1,780$ of 5,434 , Italy $24.3 \%, \mathrm{n}=841$ of 3,468 , and Ukraine $40.6 \%, \mathrm{n}=7,846$ of $19,323)$ free-roaming dogs. Respondents who answered that they would like to see no or fewer free-roaming dogs answered that this should be achieved through sheltering, CNR, and controlling the breeding of owned dogs (Fig 3). Few answered that the free-roaming dog population should be reduced through culling (Bulgaria 1.7\%, $\mathrm{n}=92$ of 4628 , Italy $1.6 \%, \mathrm{n}=56$ of 3276 , and Ukraine $7.3 \%, \mathrm{n}=1,216$ of 16586).

\section{Statistical analyses}

All models converged (for all parameters Rhat $=1.00$ and effective sample size $>1000$, see Supplementary information). There was no collinearity in the predictor variables (all values less than three). All raw model results (including the posterior mean values, standard deviations and $95 \%$ credible intervals, the $2.5 \%$ and $97.5 \%$ percentiles of the posterior distribution) are presented in S8 to S12 Tables. Estimates for mean and 95\% CIs for probabilities are reported for each model and presented in Table 2. Odds ratios (OR) are reported for predictor variables in the Bernoulli logistic regression models (Models 1 and 4).

Summary of statistical associations. Respondents were less likely to answer that they neutered their $\operatorname{dog}(\mathrm{s})$ and more likely to answer that they allow their $\operatorname{dog}(\mathrm{s})$ to roam if they identified as (i) male, (ii) religious, (iii) owning dogs for practical reasons, (iv) young, and (v) having no schooling or primary education. Respondents were more likely answer that an increase in free-roaming dogs should be prevented if they identified as (i) female, (ii) feeling threatened by free-roaming dogs, (iii) older, and (iv) having more education. Below we report the detailed statistical findings. 
A
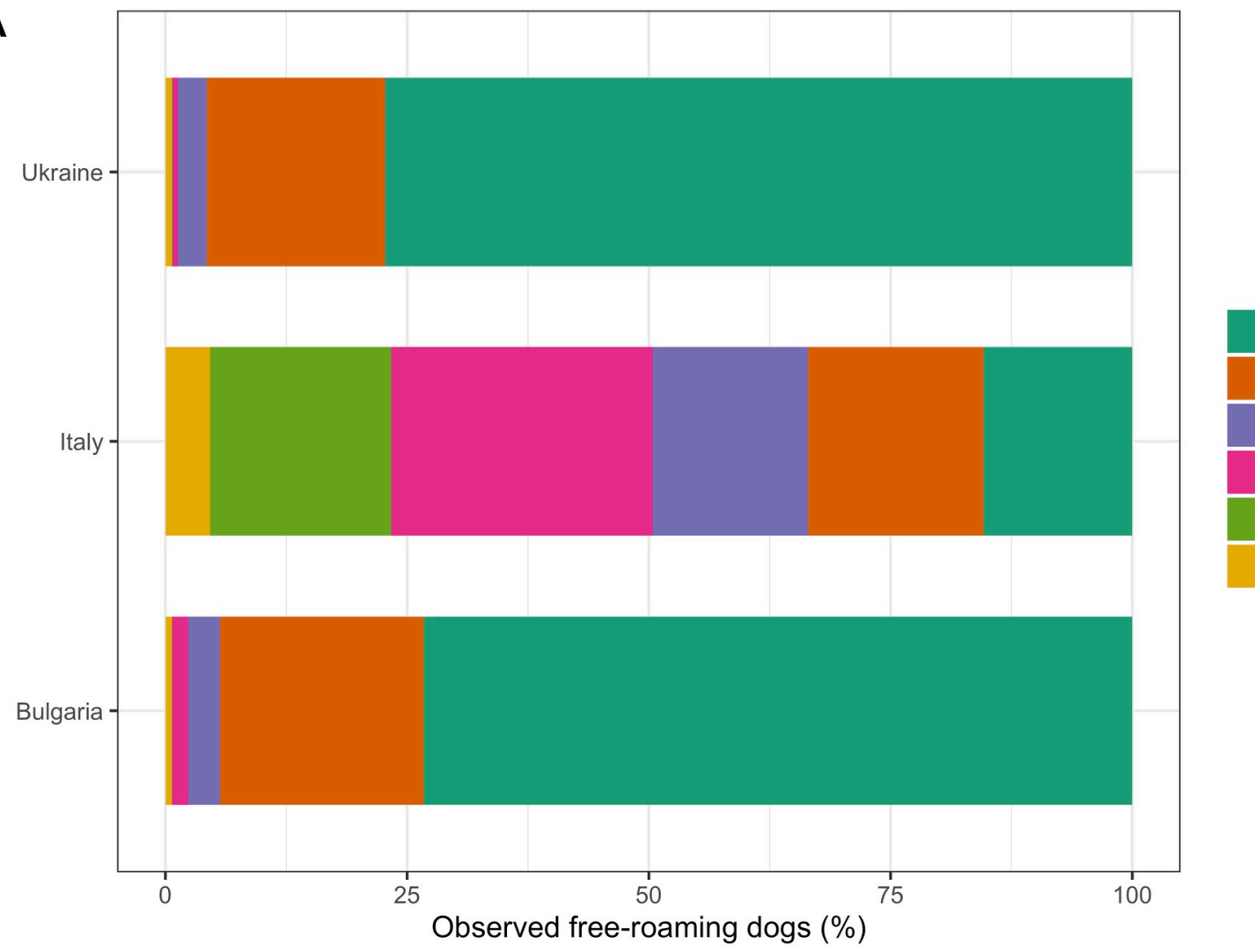

Today

In the past week

In the past month

In the past year

Never

No answer

B

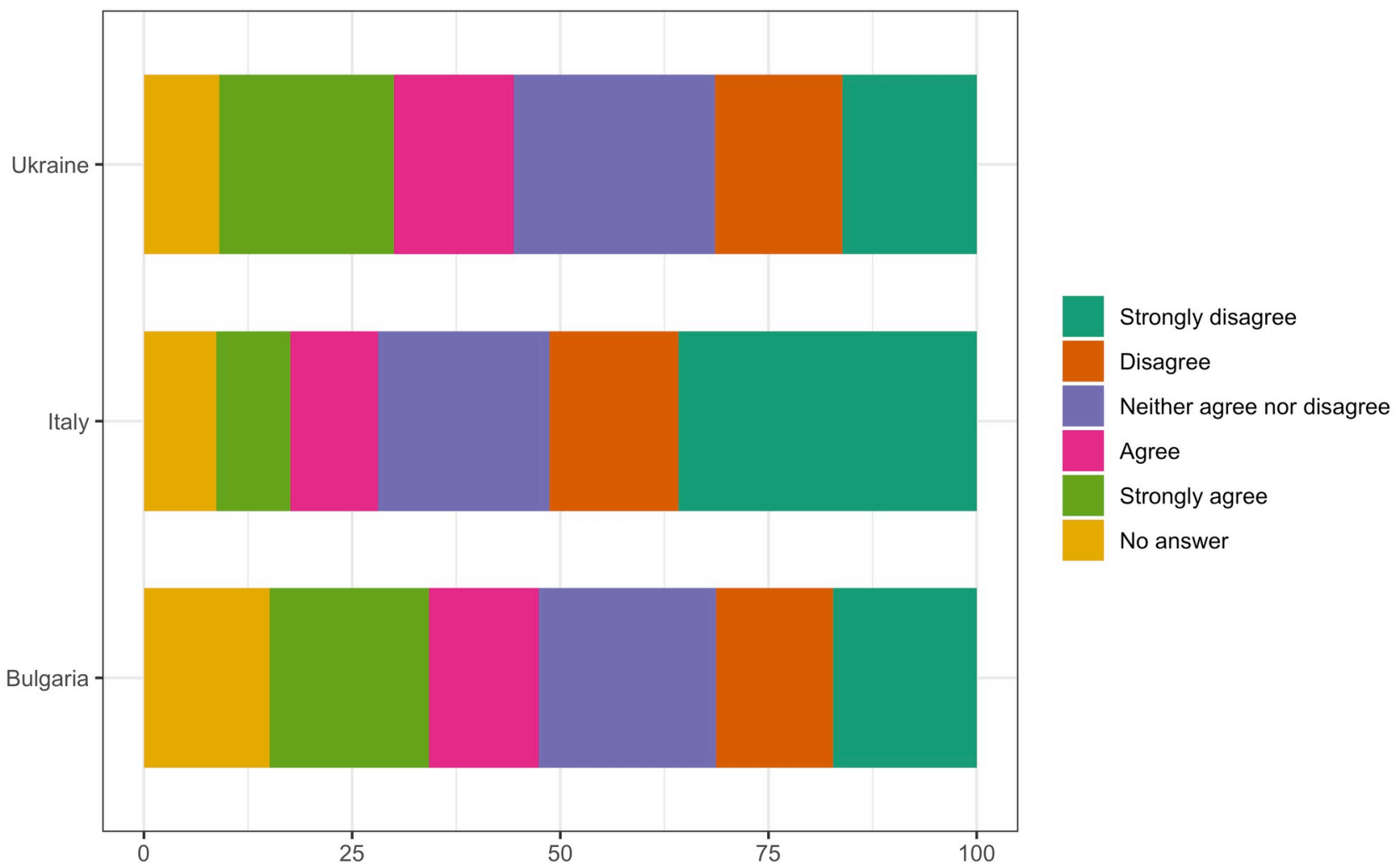

I do not like stray dogs being present in the streets around my home or work (\%) 
Fig 2. Attitudes of respondents towards free-roaming dogs in Bulgaria, Italy and Ukraine. The percentage of respondents who answered each of the answer options regarding (A) observation of free-roaming dogs and (B) agreement with statement "I do not like free-roaming dogs being present around my home or work".

https://doi.org/10.1371/journal.pone.0252368.g002

Respondent demographics and owned dog neutering status. Gender, age, education level, owning a dog for practical reasons, religious beliefs and country had significant associations with the neutering status of owned dogs (S8 Table). Probabilities of neutering are presented in Table 2. Female respondents had a higher probability of neutering, compared to males (OR 1.47; 95\% CI 1.28-1.64). Holding religious beliefs (OR 0.66, 95\% CI 0.61 to 0.72 ) and owning dogs for practical reasons (i.e. guarding or hunting, compared to for pleasure and company; OR $0.49,95 \% \mathrm{CI} 0.43$ to 0.54$)$ were both negatively associated with neutering. Respondent age (OR 1.15; 95\% CI 1.12-1.18) and education level (OR 1.29; 95\% CI 1.17-1.41) were both positively associated with neutering (i.e. the older and more educated a respondent, the more likely they were to neuter). Respondents from Italy had a higher probability of neutering compared to Bulgaria (OR 2.32; 95\% CI 2.05-2.62) and Ukraine (OR 2.73; 95\% CI 2.443.01). Respondents from Ukraine had a lower probability of neutering compared to Bulgaria (OR 0.37; 95\% CI 0.33-0.40).

Respondent demographics and owned dog roaming status. Gender, age, education level, owning a dog for practical reasons, religious beliefs, and country had significant associations with the roaming status of owned dogs (S9 Table). Probabilities of answering Never allow dog to roam for predictor variables are presented in Table 2. Females had a higher probability of answering that they Never allowed their dog to roam. Respondents who held religious beliefs, and respondents who owned dogs for practical reasons were less likely to answer Never. Age of respondent was positively correlated with answering Never (i.e. older respondents were less likely to allow their dog to roam). Increased education level of the owner was positively associated with answering Never (i.e. respondents with higher levels of education were less likely to allow their dog to roam). Respondents from Italy had the highest probability of answering Never, respondents in Bulgaria had the lowest probability of answering Never.

Respondent demographics and experience with free-roaming dogs and respondent answers to "I do not like the presence of free-roaming dogs around home or work". Predictor variables gender, age, owning a dog for practical reasons, feeling threatened by dogs on the street, having been attacked by dogs on the street, respondent or family members have been bitten by dogs on the street in last 12 months, and country were significantly associated with the statement I do not like the presence of free-roaming dogs around my home or work (S10 Table). Probabilities for answering Strongly agree for predictor variables are presented in Table 2. Female respondents had a lower probability of agreeing with the statement. Respondents who answered Yes to the question Have you ever been attacked by dogs on the street? had a higher probability of agreeing with the statement. Respondents who answered Yes to the question Have you or your family members been bitten in the last 12 months? had a higher probability of agreeing with the statement. Respondent age was positively associated with agreement to the statement (i.e. older respondents were more likely to agree). Agreement with the statement $I$ feel physically threatened by dogs on the street was positively associated with agreement with the statement $I$ do not like the presence of free-roaming dogs around my home or work (i.e. respondents who felt threatened were more likely to agree with the statement that they did not like the presence of dogs around their home or work). Respondents from Italy had the lowest probability of answering Strongly agree, and respondents from Bulgaria had the highest probability of answering Strongly agree. 


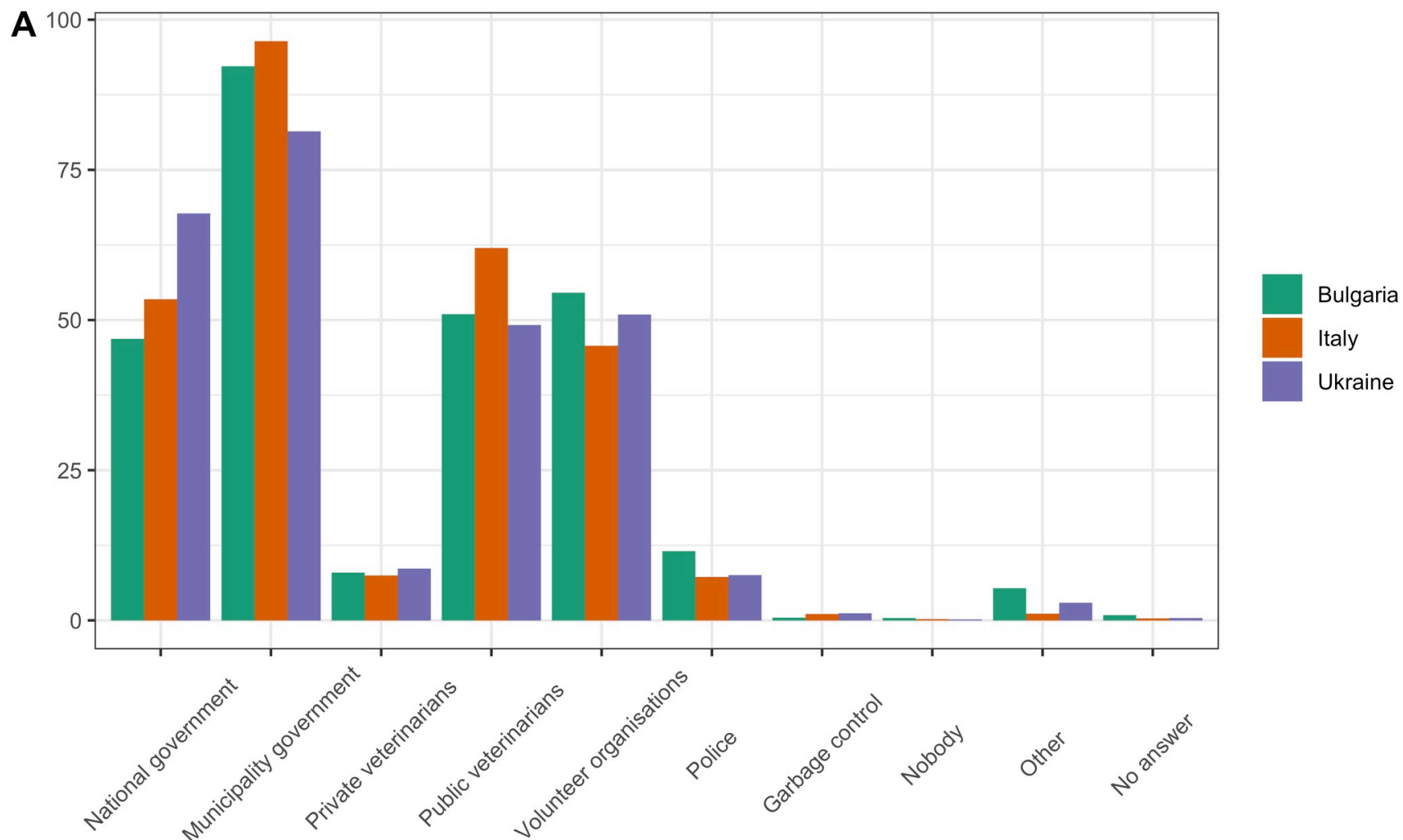

Who should be responsible for dog population managment? (\%)

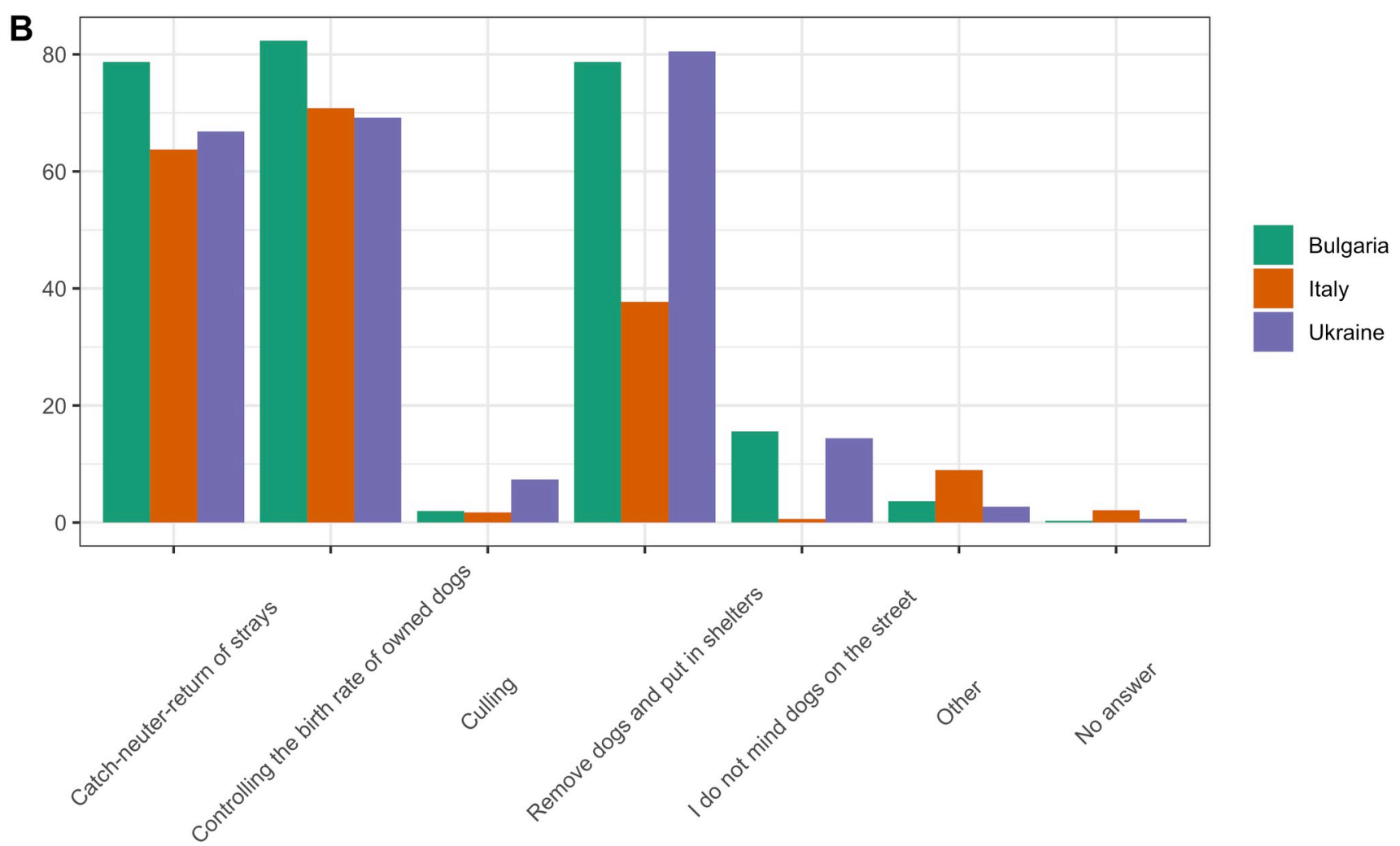

How should free-roaming dogs be reduced? (\%) 
Fig 3. Attitudes of respondents towards dog population management in Bulgaria, Italy, and Ukraine. The percentage of respondents who answered each of the answer options for: (A) who should be responsible for dog population management? and (B) how should free-roaming dogs be reduced? These were multi answer questions: Percentage of respondents who selected each answer option (i.e. 100\% would indicate that all respondents chose this option).

https://doi.org/10.1371/journal.pone.0252368.g003

There was no evidence of significant associations between: dog ownership, education level, and children in household and agreement with the statement $I$ do not like free-roaming dogs present around my home or work (S10 Table).

Respondent demographics and experience with free-roaming dogs and respondent answers to "Should an increase in free-roaming dogs should be prevented?". There were significant associations between gender, age, education level, and feeling threatened by dogs on the street and answering Yes to the question Do you think an increase in dogs on the street should be prevented? (S11 Table). Female respondents had a higher probability of answering Yes (OR 2.14; 95\% CI 1.67-2.65). There was a positive association between answering Yes and respondents' agreement with the statement "I feel physically threatened by dogs on the street" (OR 1.53 ; 95\% CI 1.37-1.68); their age (OR 1.11; 95\% CI 1.03-1.19); and education (OR 1.54; 95\% CI 1.24-1.83).

There was no evidence of significant associations between dog ownership, children in household, having been attacked by dogs on the street, respondent or family members have been bitten by dogs on the street in last 12 months or country and answering Yes to the question Do you think an increase in dogs on the street should be prevented? (S11 Table).

Associations between demographic parameters and respondent experience with the question "Would you prefer to see: No free-roaming dogs, fewer free-roaming dogs, do not mind free-roaming dogs, more free-roaming dogs". Dog ownership, gender, age, feeling threatened by dogs on the street, having been attacked by dogs on the street, respondent or family members have been bitten by dogs on the street in last 12 months, and country had significant associations with response to this question regarding preference for observing free-roaming dogs (S12 Table). Probabilities for answering No free-roaming dogs for predictor variables are presented in Table 2. Male respondents had a lower probability of answering No free-roaming dogs (Table 2). Dog owners had a higher probability of answering No free-roaming dogs. Respondents who answered Yes to the question "Have you ever been attacked by dogs on the street?", or Yes to the question "Have you or your family members been bitten in the last 12 month" or had children in their household had a higher probability of answering No freeroaming dogs. Agreement with the statement "I feel physically threatened by dogs on the street" was positively correlated with answering No free-roaming $\operatorname{dogs}$ (i.e. respondents who feel threatened by dogs on the street are more likely to answer No free-roaming dogs). Respondent age was positively correlated with answering No free-roaming dogs (i.e. older respondents had a higher probability of preferring to see No free-roaming dogs). Respondents in Italy had the highest probability of answering No free-roaming dogs, and respondents in Ukraine had the lowest probability of answering No free-roaming dogs.

There was no evidence of significant associations with children in household and education level on the probability of preference of observing free-roaming dogs (S12 Table).

\section{Discussion}

This study provides a summary of attitudes towards the presence and management of freeroaming dogs, and of dog ownership practices in Bulgaria, Italy, and Ukraine. We have also identified associations between responder characteristics and ownership practices or attitudes towards free-roaming dogs and their management in Bulgaria, Italy, and Ukraine. Respondents who identified as male, religious, owning dogs for practical reasons, young, or 
Table 2. Associations between predictor and outcome variables on the probability scale.

\begin{tabular}{|c|c|c|c|c|c|c|}
\hline \multicolumn{2}{|c|}{ Predictor variable } & \multirow{2}{*}{\begin{tabular}{|c|} 
Model 1 \\
Probability of \\
neutering (95\% \\
CI)
\end{tabular}} & \multirow{2}{*}{\begin{tabular}{|c|} 
Model 2 \\
Probability of \\
answering Never \\
allow dog to roam \\
$(95 \% \mathrm{CI})$ \\
\end{tabular}} & \multirow{2}{*}{$\begin{array}{c}\text { Model } 3 \\
\text { Probability of answering } \\
\text { Strongly agree to question "I } \\
\text { do not like the presence of free- } \\
\text { roaming dogs around home or } \\
\text { work" ( } 95 \% \mathrm{CI})\end{array}$} & \multirow{2}{*}{\begin{tabular}{|c|} 
Model 4 \\
Probability of answering \\
Yes to the question "Should \\
an increase in free-roaming \\
dogs be prevented" (95\% \\
CI)
\end{tabular}} & \multirow{2}{*}{$\begin{array}{c}\text { Model } 5 \\
\text { Probability of answering } \\
\text { No free-roaming dogs to } \\
\text { question "Would you } \\
\text { prefer to see" }(95 \% \mathrm{CI})\end{array}$} \\
\hline & & & & & & \\
\hline \multirow[t]{2}{*}{ Gender } & Male & $\begin{array}{l}0.38(0.35- \\
0.41)\end{array}$ & $0.74(0.71-0.76)$ & $0.17(0.16-0.18)$ & $0.97(0.96-0.97)$ & $0.53(0.51-0.55)$ \\
\hline & Female & \begin{tabular}{|l}
$0.48(0.47-$ \\
$0.49)$
\end{tabular} & $0.81(0.80-0.82)$ & $0.15(0.14-0.15)$ & $0.98(0.98-0.99)$ & $0.60(0.59-0.61)$ \\
\hline \multirow[t]{2}{*}{ Religious belief } & Religious & $\begin{array}{l}0.44(0.43- \\
0.45) \\
\end{array}$ & $0.79(0.78-0.80)$ & NI & NI & NI \\
\hline & \begin{tabular}{|l|}
$\begin{array}{l}\text { Non- } \\
\text { religious }\end{array}$ \\
\end{tabular} & $\begin{array}{l}0.54(0.52- \\
0.56)\end{array}$ & $0.83(0.82-0.85)$ & NI & $\mathrm{NI}$ & NI \\
\hline \multirow[t]{2}{*}{$\begin{array}{l}\text { Reason for dog } \\
\text { ownership }\end{array}$} & Practical & $\begin{array}{l}0.31(0.28- \\
0.33)\end{array}$ & $0.71(0.69-0.74)$ & NI & NI & NI \\
\hline & $\begin{array}{l}\text { Non- } \\
\text { practical }\end{array}$ & $\begin{array}{l}0.48(0.47- \\
0.49)\end{array}$ & $0.81(0.80-0.82)$ & NI & NI & NI \\
\hline \multirow{2}{*}{$\begin{array}{l}\text { Been attacked by dogs } \\
\text { on the street }\end{array}$} & Attacked & NI & NI & $0.16(0.15-0.17)$ & $0.98(0.98-0.99)$ & $0.61(0.59-0.62)$ \\
\hline & $\begin{array}{l}\text { Not } \\
\text { attacked }\end{array}$ & NI & NI & $0.15(0.14-0.15)$ & $0.98(0.98-0.99)$ & $0.59(0.58-0.59)$ \\
\hline \multirow{2}{*}{$\begin{array}{l}\text { Respondent or family } \\
\text { members have been } \\
\text { bitten by dogs on the } \\
\text { street in last } 12 \text { months }\end{array}$} & Bitten & NI & NI & $0.19(0.18-0.21)$ & $0.98(0.98-0.99)$ & $0.65(0.63-0.67)$ \\
\hline & Not bitten & NI & NI & $0.15(0.14-0.15)$ & $0.98(0.98-0.99)$ & $0.58(0.57-0.59)$ \\
\hline \multirow[t]{2}{*}{ Dog ownership } & Yes & NI & NI & $0.15(0.15-0.16)$ & $0.98(0.98-0.99)$ & $0.59(0.59-0.60)$ \\
\hline & No & NI & NI & $0.15(0.14-0.16)$ & $0.980 .98-0.99)$ & $0.56(0.55-0.57)$ \\
\hline \multirow[t]{2}{*}{ Children in household } & Yes & NI & NI & $0.15(0.15-0.16)$ & $0.98(0.98-0.99)$ & $0.59(0.58-0.60)$ \\
\hline & No & NI & $\mathrm{NI}$ & $0.15(0.14-0.15)$ & $0.98(0.98-0.99)$ & $0.59(0.57-0.59)$ \\
\hline \multirow[t]{7}{*}{ Age } & $18-24$ & $\begin{array}{l}0.40(0.39- \\
0.42)\end{array}$ & $0.78(0.76-0.79)$ & $0.14(0.14-0.15)$ & $0.98(0.98-0.98)$ & $0.57(0.56-0.58)$ \\
\hline & $25-34$ & $\begin{array}{l}0.44(0.43- \\
0.45)\end{array}$ & $0.79(0.78-0.80)$ & $0.15(0.14-0.15)$ & $0.98(0.98-0.99)$ & $0.58(0.57-0.59)$ \\
\hline & $35-44$ & $\begin{array}{l}0.47(0.46- \\
0.48)\end{array}$ & $0.80(0.80-0.81)$ & $0.15(0.15-0.16)$ & $0.98(0.98-0.99)$ & $0.59(0.58-0.60)$ \\
\hline & $45-54$ & \begin{tabular}{|l}
$0.51(0.49-$ \\
$0.52)$
\end{tabular} & $0.82(0.81-0.83)$ & $0.16(0.15-0.16)$ & $0.99(0.98-0.99)$ & $0.60(0.59-0.61)$ \\
\hline & $55-64$ & $\begin{array}{l}0.54(0.52- \\
0.56)\end{array}$ & $0.83(0.82-0.84)$ & $0.16(0.15-0.17)$ & $0.99(0.98-0.99)$ & $0.61(0.60-0.63)$ \\
\hline & $65-74$ & $\begin{array}{l}0.57(0.55- \\
0.59) \\
\end{array}$ & $0.84(0.83-0.86)$ & $0.16(0.15-0.17)$ & $0.99(0.99-0.99)$ & $0.62(0.61-0.64)$ \\
\hline & $75+$ & $\begin{array}{l}0.61(0.58- \\
0.63)\end{array}$ & $0.85(0.84-0.87)$ & $0.17(0.15-0.18)$ & $0.99(0.99-0.99)$ & $0.63(0.61-0.65)$ \\
\hline \multirow[t]{4}{*}{ Education level } & None & $\begin{array}{l}0.30(0.24- \\
0.35)\end{array}$ & $0.73(0.67-0.78)$ & $0.14(0.12-0.16)$ & $0.95(0.92-0.97)$ & $0.55(0.51-0.60)$ \\
\hline & Primary & \begin{tabular}{|l}
$0.35(0.32-$ \\
$0.39)$
\end{tabular} & $0.75(0.72-0.79)$ & $0.14(0.13-0.16)$ & $0.96(0.95-0.98)$ & $0.57(0.54-0.60)$ \\
\hline & Secondary & $\begin{array}{l}0.41(0.39- \\
0.43)\end{array}$ & $0.78(0.77-0.80)$ & $0.15(0.14-0.16)$ & $0.98(0.97-0.98)$ & $0.58(0.56-0.60)$ \\
\hline & Tertiary & $\begin{array}{l}0.48(0.47- \\
0.49)\end{array}$ & $0.81(0.80-0.82)$ & $0.15(0.15-0.16)$ & $0.98(0.98-0.99)$ & $0.60(0.58-0.60)$ \\
\hline
\end{tabular}


Table 2. (Continued)

\begin{tabular}{|c|c|c|c|c|c|c|}
\hline \multicolumn{2}{|c|}{ Predictor variable } & Model 1 & Model 2 & Model 3 & Model 4 & Model 5 \\
\hline & & $\begin{array}{c}\text { Probability of } \\
\text { neutering }(95 \% \\
\text { CI })\end{array}$ & $\begin{array}{c}\text { Probability of } \\
\text { answering Never } \\
\text { allow dog to roam } \\
(95 \% \mathrm{CI})\end{array}$ & $\begin{array}{c}\text { Probability of answering } \\
\text { Strongly agree to question "I } \\
\text { do not like the presence of free- } \\
\text { roaming dogs around home or } \\
\text { work" (95\% CI) }\end{array}$ & $\begin{array}{c}\text { Probability of answering } \\
\text { Yes to the question "Should } \\
\text { an increase in free-roaming } \\
\text { dogs be prevented" (95\% } \\
\text { CI) }\end{array}$ & $\begin{array}{l}\text { Probability of answering } \\
\text { No free-roaming dogs to } \\
\text { question "Would you } \\
\text { prefer to see" }(95 \% \mathrm{CI})\end{array}$ \\
\hline \multirow[t]{5}{*}{$\begin{array}{l}\text { Threatened by dogs on } \\
\text { the street }\end{array}$} & \begin{tabular}{|l} 
Strongly \\
disagree
\end{tabular} & NI & NI & $0.05(0.047-0.054)$ & $0.97(0.97-0.98)$ & $0.49(0.48-0.50)$ \\
\hline & Disagree & NI & NI & $0.13(0.12-0.13)$ & $0.98(0.98-0.98)$ & $0.57(0.56-0.58)$ \\
\hline & Neutral & NI & NI & $0.26(0.25-0.27)$ & $0.99(0.99-0.99)$ & $0.65(0.64-0.66)$ \\
\hline & Agree & NI & NI & $0.44(0.43-0.45)$ & $0.99(0.99-0.99)$ & $0.73(0.72-0.74)$ \\
\hline & \begin{tabular}{|l} 
Strongly \\
agree
\end{tabular} & NI & NI & $0.64(0.62-0.65)$ & $1.00(0.99-1.00)$ & $0.79(0.78-0.81)$ \\
\hline \multirow[t]{3}{*}{ Country } & Bulgaria & $\begin{array}{l}0.41(0.39- \\
0.43)\end{array}$ & $0.61(0.59-0.62)$ & $0.20(0.18-0.21)$ & $0.99(0.98-0.99)$ & $0.55(0.53-0.56)$ \\
\hline & Italy & $\begin{array}{l}0.62(0.60- \\
0.64) \\
\end{array}$ & $0.92(0.91-0.93$ & $0.10(0.10-0.11)$ & $0.98(0.98-0.99)$ & $0.76(0.74-0.77)$ \\
\hline & Ukraine & $\begin{array}{l}0.37(0.36- \\
0.38)\end{array}$ & $0.81(0.81-0.82)$ & $0.17(0.16-0.17)$ & $0.98(0.98-0.98)$ & $(0.44-0.46)$ \\
\hline
\end{tabular}

Significant results are highlighted in bold. NI = predictor variable not included in the model.

uneducated had a lower probability of neutering and a higher probability of allowing dogs to roam. Respondents who identified as: female, feeling threatened by free-roaming dogs, older, or having more education had a higher probability of answering that increases in free-roaming dog numbers should be prevented. This information could be used to target interventions towards groups who are at-risk of irresponsible dog ownership behaviours [20, 26].

\section{Ownership practices}

Responsible ownership is an important component of dog population management [19]. In order to effectively target dog population management interventions, it is important to understand the actions taken by dog owners to acquire, provide care, and relinquish ownership. Most respondents in Italy reported that they acquired their dogs from a shelter, whereas in Bulgaria and Ukraine most respondents reported acquiring their dogs from friends or by finding a dog in the street. The differences in dog acquiring behaviour could be due to a lack of public awareness of local shelters, or perceived differences in shelter quality between the study countries. However, there is currently little research to substantiate these explanations and more work on public awareness is needed. In all study countries, many respondents had adopted a dog directly from the street, potentially reflecting the prevalence of free-roaming dogs in these countries. This may also provide an explanation for the lower uptake from shelters. Where free-roaming dogs are prevalent, people may easily adopt dogs from streets near their homes, rather than travelling to a shelter to adopt a dog. Fewer respondents in Italy paid for their dog. Previous studies have suggested that dogs who are received for little cost are at higher risk of relinquishment [37]. However, the number of respondents who answered that they had given up a dog was low across the study countries. These numbers are likely to be an underestimate, given the taboo around relinquishing dogs. A study by Hsu, Severinghaus and Serpell (2003) [27] found similar estimates, where only 5.3\% of respondents answered that they had given up a dog, though far more respondents answered that they knew someone who had given up a $\operatorname{dog}(31.9 \%)$. This indicates that respondents may underreport relinquishment 
of owned dogs. Additionally, the self-selection process of recruitment for this questionnaire may result in respondents who are more highly engaged with their dog and dog ownership and less likely to relinquish their dogs.

Responsible dog ownership requires that an owner provides care for a dog until it dies or is transferred to another owner [19]. Most respondents who had relinquished a dog in Italy and Ukraine reported they had given their dog to a friend (Fig 1), complying with responsible ownership [19]. In Bulgaria, a higher percentage of respondents answered they had "Let free" their $\operatorname{dog}$ (Fig 1). Letting a dog free to the street directly increases the free-roaming dog population. Previous studies have found that respondents prefer to let a dog free to the street as it offers the dog an opportunity to live, unrestricted, outside of a shelter and offers the possibility to find another owner through adoption from the street [27]. This suggests that some dog owners may perceive letting a dog free to the street as responsible ownership. Further research is required to understand why respondents in Bulgaria chose to let a dog free, instead of giving to a shelter or to another owner.

Preventing the production of unwanted puppies is an important part of responsible ownership [19]. Most respondents answered that they prevented their dogs from reproducing; 50.8\% of respondents in Bulgaria, $65.3 \%$ in Italy, and $35.3 \%$ in Ukraine answered that they did so through neutering. This compares to study sample neutering percentages of $54 \%$ in the United Kingdom [38], and up to $80 \%$ in Australia [39,40]. The results of the present study should be interpreted with caution, as the self-selection process of recruiting for questionnaires can result in biased samples of the populations. It is possible that respondents who were more likely to neuter their dogs (such as those with higher levels of education) were more likely to complete the questionnaire. The true proportion of neutered owned dogs in the study countries may be lower. Neutering of owned dogs can prevent unwanted offspring and, if owned dogs are freeroaming, can help to prevent unowned dogs from reproducing. When respondents were asked why they did not neuter their dog, the most common answer (if one was provided) across all countries was that a dog should reproduce at least once (Fig 1). Few respondents answered that it was for cost reasons. This contrasts with previous findings in Taiwan [27] and Brazil [41], where respondents cite cost and "too much trouble" as primary reasons for not neutering. As cost, in this study, was not found to be a primary reason that owners did not neuter their dogs, this suggests that in Bulgaria, Italy, and Ukraine, whilst low-cost or free neutering interventions may be important [42], interventions should also address owner knowledge, attitudes, and practices towards reproduction, in order for interventions to have a greater impact.

Our findings of significant associations between country, gender, religious belief, reason for ownership, age, and education level and the probability of neutering (S9 Table) reflect those reported in other studies [20-24, 26]. For example, a study by Fielding (2007) in New Providence, The Bahamas [21] also found that respondents with higher levels of education were more likely to have neutered their dog. Similarly, Costa et al., (2017) [26] found that respondents with higher levels of education were more likely to answer that neutering was the best way to control the overabundance of free-roaming animals in Brazil. Respondents with higher levels of education may have a higher level of awareness of responsible ownership and the benefits of neutering, in addition to potentially having a higher income and ability to pay for neutering. Lower education levels may mean less knowledge of possible effects (and lack thereof) of reproducing on a dog's health and behaviour. Fielding, Samuels \& Mather (2002) [20] also found significant associations between owner age and neutering probability, suggesting that younger owners may have a greater desire to breed from their dog, compared to older owners. These findings suggest interventions could be targeted towards younger owners and those with a lower level of education to increase knowledge of the possible effects of neutering and awareness of responsible ownership practices. 
Owned dogs that are free-roaming directly increase the size of the free-roaming population. Owned free-roaming dogs therefore contribute to the issues, such as the risks to public health $[43,44]$ and wildlife [11, 12, 45-49]. Efforts encouraging responsible ownership may help reduce the number of dogs roaming, and may therefore help to reduce the impacts of the freeroaming dogs on public health and wildlife [19]. This study found evidence for significant associations between gender, religious beliefs, reason for dog ownership, age, education, and country, and the probability of allowing owned dogs to roam (S9 Table). It is clear from these results that interventions should be targeted using these demographic risk factors to prevent roaming behaviour, particularly in countries where higher percentages of owned dogs are freeroaming, such as Bulgaria and Ukraine.

Most respondents (59-92\%) across all three countries answered that they never allowed their dogs to roam (S5 Table). Again, these results might be biased, as more highly engaged dog owners may have been more likely to participate in this study and may also be less likely to allow their dogs to roam. The results are higher than those reported in studies using similar sampling approaches (i.e. relying on voluntary participation in questionnaires/interviews) in the Bahamas 57\% [50], Bhutan 50\% [51], Cameroon 37.7\% [52], Guatemala 25.7\% [53], urban households in Haiti 54\% [54], Kenya 19\% [55], Mexico 44.9\% [56], Ethiopia 15.7\% [57], Tanzania 22\% [58], and Uganda 21.7\% [59], but lower than those reported in semi-urban households in Haiti 62\% [54] and Taiwan 79\% [27]. There was a significant association between study country and roaming probability ( $99 \mathrm{Table}$ ), with respondents in Bulgaria more likely to allow their dogs to roam, compared to Italy and Ukraine. The significant association with country may reflect differences in dog ownership practices and attitudes between the study countries.

\section{Attitudes towards free-roaming dogs}

In Bulgaria and Ukraine, almost all respondents answered that they had seen free-roaming dogs on the street, whereas in Italy $18.7 \%$ of respondents had never seen a free-roaming dog (Fig 2). These results may indicate that the populations of free-roaming dogs are larger in Bulgaria and Ukraine. Within Italy, there are differences in dog population management: some regions permit CNR and the presence of "community dogs" (free-roaming dogs owned by the municipality), whilst other regions only permit dog population management through sheltering. Respondents living in regions that do not permit community dogs, or in regions with smaller free-roaming dog populations, may be expected to observe fewer free-roaming dogs. Higher percentages of respondents in Bulgaria and Ukraine answered that they felt threatened by free-roaming dogs, and that they or a member of their family had been bitten in the last 12 months. These results may also indicate a greater free-roaming dog population size and related problems in Bulgaria and Ukraine.

A large proportion of respondents across all countries answered that they provided care for free-roaming dogs (S6 Table). For example, $90.6 \%$ in Bulgaria, 53.7\% in Italy, and $67.5 \%$ of respondents in Ukraine answered that they provided food for free-roaming dogs. For Bulgaria and Ukraine, these numbers are similar to those reported by Costa et al., (2015) in Brazil, where $61.9 \%$ of respondents reported that they or their neighbours fed free-roaming animals, and Massei et al., (2017) [60] in Nepal, where 47\% of respondents provided food and care for free-roaming dogs. In a previous study by Slater et al., (2008) [61] in central Italy, only 5\% of respondents reported that they provided care for free-roaming dogs. This is much lower than the numbers reported in this study, where $71.5 \%$ of Italian respondents answered that they provided care for free-roaming dogs. This may be explained by the potential bias in the recruitment process of this study, respondents who provide care for free-roaming dogs may also have been more motivated to complete the questionnaire. Data was collected by Slater et al., (2008) 
using an anonymous telephone survey and had a high response rate (74\%). Providing care for free-roaming dogs is controversial. Providing food may alleviate welfare issues associated with lack of nutrition in the free-roaming dog population [62-64], but also increases the carrying capacity for the free-roaming dog population.

Most respondents across all study countries felt that the municipal government and volunteer organisations should be responsible for managing free roaming dog populations, and mostly by methods such as sheltering, CNR, and by controlling the breeding of owned dogs (Fig 3). These results are similar to those found in previous studies $[61,65,66]$. For example, a study by Ortega-Pacheco et al., (2007) [66] in Yucatan, Mexico found that $52.8 \%$ of interviewed households supported the neutering of dogs for dog population management, and felt that the government and society were responsible for dog population management. The results in this study suggest there is support for dog population management through sheltering, $\mathrm{CNR}$, and restricted breeding of owned dogs. Few respondents answered that culling should be used to control the free-roaming dog population (Fig 3). These results are similar to those found by Beckman et al., (2014) [65], but are much lower than results by Costa et al., (2017) [26], where culling was supported by $26.8 \%$ of respondents.

As attitudes can play an important role in determining the success of dog population management, it is important that organisations involved in dog population management gauge the level of support for reducing free-roaming dogs in the area. Across all three countries, most respondents answered that they would prefer to see fewer or no free-roaming dogs, and that an increase in free-roaming dogs should be prevented. With regards to Italy, these responses correspond with previously reported attitudes in the Teramo province in the Abruzzo region of Italy [61].

\section{Implications for future interventions}

The results of this study suggest that there is a preference in all three study countries for a reduction in free-roaming dog numbers, and for this to be achieved through sheltering, CNR and responsible ownership, rather than culling. There is therefore support for the management interventions that are taking place in these study countries. Targeted interventions that can influence the behaviour of those less likely to practice responsible ownership may help to improve responsible ownership and reduce free-roaming dog numbers. For example, as there was evidence for significant associations between gender and age on response variables roaming and neutering, interventions could be adapted to target men and younger people on responsible ownership practices. For example, interventions could target these groups to increase knowledge of the necessity to neuter dogs and possible effects of neutering on dog health and behaviour.

Questionnaires are important tools for evaluating the impact of interventions on human attitudes and dog ownership practices. This includes monitoring attitudes and behaviour (such as responsible ownership) to determine whether education campaigns are having a significant impact. There have been numerous studies on attitudes towards free-roaming dogs and dog ownership practices, but few repeated surveys to assess the effectiveness of dog population control on human attitudes and dog ownership practices [26, 67]. The results from this present study can be used to target interventions to those who are less likely to practice responsible ownership and the results can also be used as a baseline for monitoring the effect of dog population management interventions on dog ownership behaviours and attitudes in Bulgaria, Italy, and Ukraine.

\section{Limitations of questionnaire research methods}

As discussed throughout, there are limitations in using questionnaires to determine attitudes and behaviours. The self-selection process involved in the recruitment for questionnaires can 
result in a biased sample of the target population, as certain members of the public may be more motivated to complete the questionnaire, for example dog owners, or those with strong views about the subject. In this questionnaire, as with other similarly themed questionnaire [61], a high percentage of the respondents were female. As there were fewer responses from men, the questionnaire results may not necessarily reflect the views of the wider population. A high percentage of respondents reported to have or be in tertiary education, which is not representative of the wider populations. The questionnaire was also primarily advertised through social media; therefore, members of the public who do not have access to social media are likely to have been missed. Although this is a limitation, social media provides opportunities to recruit a large and diverse range of respondents (see $[68,69]$ for review). We used four different adverts with slightly different wording in order to attract as many respondents as possible. The different adverts may have attracted different subsets of people, which could lead to biases in results. Though we were unable to determine which adverts respondents saw, all adverts were distributed equally across the three countries and are unlikely to lead to differences between countries.

In questionnaire surveys, missing data can occur at two levels: (i) missing data of the complete questionnaire (as described above), and (ii) missing data when respondents do not complete specific questions or sections. In this study, higher percentages of missing responses were observed (S1 Table) for questions relating to the respondents' religion (13.3\%), whether they did not like the presence of free-roaming dogs (10.2\%), and if they felt threatened by freeroaming dogs around their home or work (8.2\%). This missing data can result in biased estimates, and as such, these results should be interpreted with caution. Despite the clear biases in questionnaire surveys, given the range of respondents in this study (for example, in terms of ages and regions), the results provide an indication of ownership practices and attitudes, and the statistical models still give us information about the risk factors for behaviours and attitudes.

\section{Conclusions}

When planning dog population management interventions, it is important to understand how human behaviour may impact the success of an intervention. This involves understanding how dog ownership practices may influence intervention success, and gauging the level of public support for management interventions. This study found evidence for significant associations between demographic factors and ownership practices and respondent attitudes. These results can be used to inform future dog population management interventions in these countries. Interventions should consider also carrying out periodic questionnaire surveys to evaluate changes in respondent attitudes towards responsible ownership and the free-roaming dog population.

\section{Supporting information}

S1 File. Facebook adverts. (DOCX)

S2 File. English copy of questionnaire. (DOCX)

S3 File. Answer option to question "Are your dog(s) registered and identified" in Bulgarian questionnaire.

(DOCX) 
S1 Table. Number of "No responses" to outcome and predictor variables in statistical analysis. (DOCX)

S2 Table. Demographic information about respondents in Bulgaria, Italy and Ukraine. (DOCX)

S3 Table. Number of respondents in Bulgaria, split by oblasts in Bulgaria. (DOCX)

S4 Table. Number of respondents in Italy, split by regions in Italy. (DOCX)

S5 Table. Number of respondents in Ukraine, split by oblasts in Ukraine. (DOCX)

S6 Table. Respondents answers to questions about ownership practices in Bulgaria, Italy and Ukraine.

(DOCX)

S7 Table. Respondents answers to questions about attitudes to free-roaming dogs in Bulgaria, Italy and Ukraine.

(DOCX)

S8 Table. The posterior mean values, error estimates, the 2.5 and 97.5 percentiles of the posterior distribution (CI), Rhat values and bulk and tail effective sample sizes (ESS) for Model 1.

(DOCX)

S9 Table. The posterior mean values, error estimates, the 2.5 and 97.5 percentiles of the posterior distribution (CI), Rhat values and bulk and tail effective sample sizes (ESS) for Model 2.

(DOCX)

S10 Table. The posterior mean values, error estimates, the 2.5 and 97.5 percentiles of the posterior distribution (CI), Rhat values and bulk and tail effective sample sizes (ESS) for Model 3.

(DOCX)

S11 Table. The posterior mean values, error estimates, the 2.5 and 97.5 percentiles of the posterior distribution (CI), Rhat values and bulk and tail effective sample sizes (ESS) for Model 4.

(DOCX)

S12 Table. The posterior mean values, error estimates, the 2.5 and 97.5 percentiles of the posterior distribution (CI), Rhat values and bulk and tail effective sample sizes (ESS) for Model 5.

(DOCX)

\section{Acknowledgments}

We thank Sarah Ross, Benjamin Cueni, Alesya Lischyshyna, Greta Berteselli, and Matteo Chincarini for providing support with Facebook advertising and translation and all survey respondents for contributing to the study. We are also grateful to the reviewers for providing useful feedback on this paper, and to Dr Helen Gray, Dr Conor Goold, and Dr Mary Friel for reviewing draft versions and providing important feedback on statistical methods. 


\section{Author Contributions}

Conceptualization: Lauren Margaret Smith, Rupert Quinnell, Alexandru Munteanu, Sabine Hartmann, Paolo Dalla Villa, Lisa Collins.

Data curation: Lauren Margaret Smith.

Formal analysis: Lauren Margaret Smith.

Methodology: Lauren Margaret Smith, Rupert Quinnell, Lisa Collins.

Supervision: Rupert Quinnell, Lisa Collins.

Writing - original draft: Lauren Margaret Smith.

Writing - review \& editing: Lauren Margaret Smith, Rupert Quinnell, Alexandru Munteanu, Sabine Hartmann, Paolo Dalla Villa, Lisa Collins.

\section{References}

1. Hughes J, Macdonald DW. A review of the interactions between free-roaming domestic dogs and wildlife. Biol Conserv. 2013; 157: 341-351. https://doi.org/10.1016/j.biocon.2012.07.005

2. Gompper M. The dog-human-wildlife interface: assessing the scope of the problem. Gompper ME, editor. Oxford: Oxford University Press, UK; 2014.

3. Jimenez S, Perez A, Gil H, Schantz PM, Ramalle E, Juste RA. Progress in control of cystic echinococcosis in La Rioja, Spain: decline in infection prevalences in human and animal hosts and economic costs and benefits. Acta Trop. 2002; 83: 213-221. https://doi.org/10.1016/s0001-706x(02)00091-8 PMID: 12204394

4. Economides $\mathrm{P}$, Christofi $\mathrm{G}$. Experience gained and evaluation of the Echinococcosis/Hydatidosis eradication programmes in Cyprus 1971-1999. In: Craig P and Pawlowski Z, editor. Cestode Zoonoses: Echinococcosis and cysticercosis: an ermergent and global problem. Amsterdam, The Netherlands: IOS Press; 2002. pp. 367-379.

5. Morters MK, McKinley TJ, Restif O, Conlan AJK, Cleaveland S, Hampson K, et al. The demography of free-roaming dog populations and applications to disease and population control. J Appl Ecol. 2014; 51: 1096-1106. https://doi.org/10.1111/1365-2664.12279 PMID: 25657481

6. Home C, Pal R, Sharma R, Suryawanshi K, Bhatnagar Y, Vanak A. Commensal in conflict: Livestock depredation patterns by free-ranging domestic dogs in the Upper Spiti Landscape, Himachal Pradesh, India. R Swedish Acad Sci. 2017; 46: 655-666. https://doi.org/10.1007/s13280-016-0858-6 PMID: 28074403

7. Ciucci P, Luigi B. Wolf and Dog Depredation on Livestock in Central Italy. Wildl Soc Bull. 1998; 26: 504514.

8. Blair B, Townsend T. Dog Predation of Domestic Sheep in Ohio. J Range Manag. 1983; 36: 527-528.

9. Bergman DL, Breck SW, Bender SC. Dogs gone wild: Feral dog damage in the United States. The Thirteenth Wildlife Damage Management Conference 5th April 2009. Saratoga Springs, NY, USA; 2009. pp. 177-183.

10. Wierzbowska IA, Hedrzak M, Popczyk B, Okarma H, Crooks KR. Predation of wildlife by free-ranging domestic dogs in Polish hunting grounds and potential competition with the grey wolf. Biol Conserv. 2016; 201: 1-9. https://doi.org/10.1016/j.biocon.2016.06.016

11. Haydon DT, Laurenson MK, Sillero-Zubiri C. Integrating epidemiology into population viability analysis: managing the risk posed by rabies and canine distemper to the Ethiopian wolf. Conserv Biol. 2002; 16: 1372-1385.

12. Newsome TM, Stephens D, Ballard G-A, Dickman CR, Fleming PJS. Genetic profile of dingoes (Canis lupus dingo) and free-roaming domestic dogs (C. I. familiaris) in the Tanami Desert, Australia. Wildl Res. 2013; 40: 196-206. https://doi.org/10.1071/WR12128

13. Doherty TS, Dickman CR, Glen AS, Newsome TM, Nimmo DG, Ritchie EG, et al. The global impacts of domestic dogs on threatened vertebrates. Biol Conserv. 2017; 210: 56-59. https://doi.org/10.1016/j. biocon.2017.04.007

14. Fielding W, Mather J. Stray dogs in an island community: A case study from New Providence, The Bahamas. J Appl Anim Welf Sci. 2000; 3: 305-319. 
15. Rodriguez-Vivas R.I., Ortega-Pacheco A, Rosado-Aguilar. J.A. BGME. Factors affecting the prevalence of mange-mite infestations in stray dogs of Yucatán, Mexico. Parasitology. 2003; 115: 61-65. https://doi.org/10.1016/s0304-4017(03)00189-4 PMID: 12860068

16. HSI. Case study of an incentive program to encourage the sterilization of dogs (and cats) and greater attention to animal welfare on Abaco Island in the Bahamas. Washington, D.C; 2001.

17. Macpherson C, Meslin FX, Wandeler AI. Dog Ecology and Population Biology. In: Macpherson C, Meslin FX, Wandeler Al, editors. Dogs, zoonoses and public health. New York: CABI Publishing; 2002. pp. 17-62.

18. Dalla Villa P, Kahn S, Stuardo L, lannetti L, Di Nardo A, Serpell JA. Free-roaming dog control among OIE-member countries. Prev Vet Med. 2010; 97: 58-63. https://doi.org/10.1016/j.prevetmed.2010.07. 001 PMID: 20709415

19. World Organisation for Animal Health(OIE). Stray dogs population control. Terrestrial Animal Health Code, 24th Ed. OIE, Paris 2019 pp. 1-12.

20. Fielding WJ, Samuels D, Mather J. Attitudes and actions of West Indian dog owners towards neutering their animals: A gender issue? Anthrozoos. 2002; 15: 206-226. https://doi.org/10.2752/ 089279302786992487

21. Fielding $\mathrm{W}$. Knowledge of the welfare of nonhuman animals and prevalence of dog care practices in New Providence, The Bahamas. J Appl Anim Welf Sci. 2007; 10: 153-168. https://doi.org/10.1080/ 10888700701313587 PMID: 17559322

22. McKay SA, Farnworth MJ, Waran NK. Current attitudes toward, and incidence of, sterilization of cats and dogs by caregivers (owners) in Auckland, New Zealand. J Appl Anim Welf Sci. 2009; 12: 331-344. https://doi.org/10.1080/10888700903163617 PMID: 20183485

23. Blackshaw J, Day C. Attitudes of dog owners to neutering pets: demographic data and effects of owner attitudes. Aust Vet J. 1994; 71: 113-116. https://doi.org/10.1111/j.1751-0813.1994.tb03351.x PMID: 8048906

24. Wongsaengchan $C$, McKeegan DEF. The views of the UK public towards routine neutering of dogs and cats. Animals. 2019; 9: 1-16. https://doi.org/10.3390/ani9040138 PMID: 30986979

25. Driscoll K. Attitudes towards animal use. Anthrozoos. 1992; 5: 32-39.

26. Costa ED, Martins CM, Cunha GR, Catapan DC, Ferreira F, Oliveira ST, et al. Impact of a 3-year pet management program on pet population and owner's perception. Prev Vet Med. 2017; 139: 33-41. https://doi.org/10.1016/j.prevetmed.2017.01.001 PMID: 28364830

27. Hsu Y, Severinghaus LL, Serpell JA. Dog Keeping in Taiwan: Its Contribution to the Problem of FreeRoaming. J Appl Anim Welf Sci. 2003; 6: 1-23. https://doi.org/10.1207/S15327604JAWS0601_01 PMID: 12795855

28. Online surveys. [cited 18 Nov 2019]. Available: https://www.onlinesurveys.ac.uk/

29. Facebook. [cited 18 Nov 2019]. Available: https://www.facebook.com/

30. Twitter. [cited 18 Nov 2019]. Available: https://twitter.com/

31. Liddell TM, Kruschke JK. Analyzing ordinal data with metric models: What could possibly go wrong? J Exp Soc Psychol. 2018; 79: 328-348. https://doi.org/10.1016/j.jesp.2018.08.009

32. Likert R. A technique for the measurement of attitudes. Arch Psychol. 1932; $22: 55$.

33. Stevens SS. On the theory of scales of measurement. Science (80-). 1946; 103: 677-680. https://doi. org/10.1126/science.103.2684.677

34. Bürkner PC. brms: An R package for Bayesian multilevel models using Stan. J Stat Softw. 2017; 80: 128. https://doi.org/10.18637/jss.v080.i01

35. R Core Team. R: A language and environment for statistical computing. R Foundation for Statistical Computing, Vienna, Austria. 2013.

36. Fox J, Weisberg S. An R Companion to Applied Regression. Third. Thousand Oaks, CA: Sage; 2019.

37. New JC, Salman MD, King M, Scarlett JM, Kass PH, Hutchison JM. Characteristics of Shelter-Relinquished Animals and Their Owners Compared With Animals and Their Owners in U.S. Pet-Owning Households. J Appl Anim Welf Sci. 2000; 3: 179-201.

38. Diesel G, Brodbelt D, Laurence C. Survey of veterinary practice policies and opinions on neutering dogs. Vet Rec. 2010; 166: 455-458. https://doi.org/10.1136/vr.b4798 PMID: 20382933

39. Rohlf VI, Bennett PC, Toukhsati S, Coleman G. Why Do Even Committed Dog Owners Fail to Comply with Some Responsible Ownership Practices? Anthrozoos. 2010; 23: 143-155. https://doi.org/10.2752/ $175303710 X 12682332909972$ 
40. Bennett PC, Rohlf VI. Owner-companion dog interactions: Relationships between demographic variables, potentially problematic behaviours, training engagement and shared activities. Appl Anim Behav Sci. 2007; 102: 65-84. https://doi.org/10.1016/j.applanim.2006.03.009

41. Santos Baquero O, Marconcin S, Rocha A, Maria Garcia R de C. Companion animal demography and population management in Pinhais, Brazil. Prev Vet Med. 2018; 158: 169-177. https://doi.org/10.1016/ j.prevetmed.2018.07.006 PMID: 30220391

42. Kass $\mathrm{PH}$, Johnson $\mathrm{KL}$, Weng HY. Evaluation of animal control measures on pet demographics in Santa Clara County, California, 1993-2006. PeerJ. 2013; 1: 1-15. https://doi.org/10.7717/peerj.18 PMID: 23638352

43. Tenzin T, Ahmed R, Debnath NC, Ahmed G, Yamage M. Free-Roaming Dog Population Estimation and Status of the Dog Population Management and Rabies Control Program in Dhaka City, Bangladesh. PLoS Negl Trop Dis. 2015; 9: 1-14. https://doi.org/10.1371/journal.pntd.0003784 PMID: 25978406

44. Rinzin K, Tenzin T, Robertson I. Size and demography pattern of the domestic dog population in Bhutan: Implications for dog population management and disease control. Prev Vet Med. 2016; 126: 39-47. https://doi.org/10.1016/j.prevetmed.2016.01.030 PMID: 26873612

45. Ritchie E, Dickman C, Letnic M, Vanak AT. Dogs as predators and trophic regulators. In: Gompper ME, editor. Free-ranging dogs and wildlife conservation. Oxford: Oxford University Press; 2014. pp. 55-68.

46. Vial F, Cleaveland S, Rasmussen G, Haydon DT. Development of vaccination strategies for the management of rabies in African wild dogs. Biol Conserv. 2006; 131: 180-192.

47. Cleaveland S, Appel MG., Chalmers WS., Chillingworth C, Kaare M, Dye C. Serological and demographic evidence for domestic dogs as a source of canine distemper virus infection for Serengeti wildlife. Vet Microbiol. 2000; 72: 217-227. https://doi.org/10.1016/s0378-1135(99)00207-2 PMID: 10727832

48. Vilà C, Wayne R. Hybridization between wolves and dogs. Conserv Biol. 1999; 13: 195-198.

49. Sundqvist A-K, Ellegren $\mathrm{H}$, Vila $\mathrm{C}$. Wolf or dog? Genetic identification of predators from saliva collected around bite wounds' on prey. Conserv Genet. 2008; 9: 1275-1279. https://doi.org/10.1007/s10592007-9454-4

50. Fielding WJ, Plumridge SJ. Characteristics of owned dogs on the island of New Providence, The Bahamas. J Appl Anim Welf Sci. 2005; 8: 245-260. https://doi.org/10.1207/s15327604jaws0804_2 PMID: 16436029

51. Tenzin T, Namgyal J, Letho S. Community-based survey during rabies outbreaks in Rangjung town, Trashigang, eastern Bhutan, 2016. BMC Infect Dis. 2017; 17: 1-5. https://doi.org/10.1186/s12879-0162122-x PMID: 28049444

52. Costa G, Gilbert A, Monroe B, Blanton J, Ngam Ngam S, Recuenco S, et al. The influence of poverty and rabies knowledge on healthcare seeking behaviors and dog ownership, Cameroon. Rupprecht CE, editor. PLoS One. 2018; 13: 1-19. https://doi.org/10.1371/journal.pone.0197330 PMID: 29927935

53. Pulczer AS, Jones-Bitton A, Waltner-Toews D, Dewey CE. Owned dog demography in Todos Santos Cuchumatán, Guatemala. Prev Vet Med. 2013; 108: 209-217. https://doi.org/10.1016/j.prevetmed. 2012.07.012 PMID: 22906504

54. Schildecker S, Millien M, Blanton JD, Boone J, Emery A, Ludder F, et al. Dog Ecology and Barriers to Canine Rabies Control in the Republic of Haiti, 2014-2015. Transbound Emerg Dis. 2016; 64: 14331442. https://doi.org/10.1111/tbed.12531 PMID: 27313170

55. Kitala P, McDermott J, Kyule M, Gathuma J, Perry B, Wandeler A. Dog ecology and demography information to support the planning of rabies control in Machakos District, Kenya. Acta Trop. 2001; 78: $217-$ 230. https://doi.org/10.1016/s0001-706x(01)00082-1 PMID: 11311185

56. Kisiel LM, Jones-Bitton A, Sargeant JM, Coe JB, Flockhart DTT, Reynoso Palomar A, et al. Owned dog ecology and demography in Villa de Tezontepec, Hidalgo, Mexico. Prev Vet Med. 2016; 135: 37-46. https://doi.org/10.1016/j.prevetmed.2016.10.021 PMID: 27931927

57. Tschopp R, Bekele S, Aseffa A. Dog Demography, Animal Bite Management and Rabies KnowledgeAttitude and Practices in the Awash Basin, Eastern Ethiopia. PLoS Negl Trop Dis. 2016; 10: 1-14. https://doi.org/10.1371/journal.pntd.0004471 PMID: 26900855

58. Sambo M, Lembo T, Cleaveland S, Ferguson HM, Sikana L, Simon C, et al. Knowledge, Attitudes and Practices (KAP) about Rabies Prevention and Control: A Community Survey in Tanzania. PLoS Negl Trop Dis. 2014; 8: 1-10. https://doi.org/10.1371/journal.pntd.0003310 PMID: 25473834

59. Wallace RML, Mehal J, Nakazawa Y, Recuenco S, Bakamutumaho B, Osinubi M, et al. The impact of poverty on dog ownership and access to canine rabies vaccination: Results from a knowledge, attitudes and practices survey, Uganda 2013. Infect Dis Poverty. 2017; 6: 1-22. https://doi.org/10.1186/s40249016-0216-8 PMID: 28160773 
60. Massei G, Fooks AR, Horton DL, Callaby R, Sharma K, Dhakal IP, et al. Free-Roaming Dogs in Nepal: Demographics, Health and Public Knowledge, Attitudes and Practices. Zoonoses Public Health. 2017; 64: 29-40. https://doi.org/10.1111/zph.12280 PMID: 27334892

61. Slater MR, Di Nardo A, Pediconi O, Villa PD, Candeloro L, Alessandrini B, et al. Free-roaming dogs and cats in central Italy: Public perceptions of the problem. Prev Vet Med. 2008; 84: 27-47. https://doi.org/ 10.1016/j.prevetmed.2007.10.002 PMID: 18055046

62. Totton SC, Wandeler AI, Ribble CS, Rosatte RC, McEwen SA. Stray dog population health in Jodhpur, India in the wake of an animal birth control (ABC) program. Prev Vet Med. 2011; 98: 215-220. https:// doi.org/10.1016/j.prevetmed.2010.11.011 PMID: 21144606

63. Butler JRA, Brown WY, du Toit JT. Anthropogenic Food Subsidy to a Commensal Carnivore: The Value and Supply of Human Faeces in the Diet of Free-Ranging Dogs. Animals. 2018; 8: 1-16. https://doi.org/ 10.3390/ani8050067 PMID: 29702585

64. Rautenbach GH, Boomker J, De Villiers IL. A descriptive study of the canine population in a rural town in southern africa. J S Afr Vet Assoc. 1991; 62: 158-162. PMID: 1770490

65. Beckman M, Hill KE, Farnworth MJ, Bolwell CF, Bridges J, Acke E. Tourists' perceptions of the freeroaming dog population in Samoa. Animals. 2014; 4: 599-611. https://doi.org/10.3390/ani4040599 PMID: 26479002

66. Ortega-Pacheco A, Rodriguez-Buenfil JC, Bolio-Gonzalez ME, Sauri-Arceo CH, Jiménez-Coello M, Forsberg CL. A survey of dog populations in Urban and rural areas of Yucatan, Mexico. Anthrozoos. 2007; 20: 261-274. https://doi.org/10.2752/089279307X224809

67. Boey J. Working with communities to improve the quality of life of British Columbia's free-roaming dogs and their people. Masters Thesis. University of Victoria. 2017.

68. Pedersen ER, Kurz J. Using Facebook for health-related research study recruitment and program delivery. Curr Opin Psychol. 2016; 9: 38-43. https://doi.org/10.1016/j.copsyc.2015.09.011 PMID: 26726313

69. Kosinski M, Matz SC, Gosling SD, Popov V, Stillwell D. Facebook as a research tool for the social sciences: Opportunities, challenges, ethical considerations, and practical guidelines. Am Psychol. 2015; 70: 543-556. https://doi.org/10.1037/a0039210 PMID: 26348336 